\title{
Cultivo de tambaqui (Colossoma macropomum) em tanques-rede: Aspectos técnicos
}

\author{
Cultivation of tambaqui (Colossoma macropomum) in net tanks: Technical aspects \\ Cultivo de tambaqui (Colossoma macropomum) en jaula: Aspectos técnicos
}

Recebido: 25/06/2021 | Revisado: 04/07/2021 | Aceito: 05/07/2021 | Publicado: 16/07/2021

Jânderson Rocha Garcez
ORCID: https://orcid.org/0000-0001-8216-9501
Instituto Federal de Educação, Ciência e Tecnologia do Amazonas, Brasil
E-mail: janderson.garcez@ifam.edu.br
Victor Santos Lira da Nóbrega
ORCID: https://orcid.org/0000-0002-8769-170X
Universidade Estadual do Oeste do Paraná, Brasil
E-mail: victorlira23@ outlook.com
Thais Patricio Torres
ORCID: https://orcid.org/0000-0002-3067-4028
Universidade Estadual do Oeste do Paraná, Brasil
E-mail: thaisptoorres@ @mail.com
Arcangelo Augusto Signor
ORCID: https://orcid.org/0000-0003-4686-3488
E-mail: arcangelo.signor@ifpr.edu.br

\section{Resumo}

O tambaqui (Colossoma macropomum) é uma espécie nativa da Amazônia que apresenta bom desempenho zootécnico em criação intensiva. O intuito deste trabalho foi verificar os principais aspectos relacionados ao cultivo do $C$. macropoтиm em tanques-rede, como local de instalação adequado, facilidade do manejo, usos de rações e características físicas, químicas e biológicas do ambiente, relacionando com as potencialidades e desafios do cultivo desta espécie. Para alevinagem, é necessário um berçário tipo bolsão e posteriormente realizar repicagem para manter a homogeneidade do tamanho do peso dos peixes. O ciclo de criação dura de 4 a 10 meses, dependendo do peso do produto desejado, sendo dividido em duas fases: recria e terminação. Os principais fatores que podem potencializar o crescimento de C. macropomum durante o ciclo de produção é a densidade de estocagem, a alimentação e a qualidade da água, juntamente com a adoção de boas práticas de manejo sanitário e o melhor controle de prevenção às enfermidades. O tambaqui tipo "curumim" é o principal produto comercializado oriundos de tanques-rede, é comumente comercializado in natura, como peixe fresco ou congelado, apresenta bom rendimento de carcaça e possui boa aceitação pelas indústrias de refeições coletivas. A criação apresenta riscos econômicos, pois os preços comercializados são próximos ao custo de produção. Para o sucesso da atividade são necessários mão-de-obra capacitada, assistência técnica especializada, extensão rural a pequenos produtores para domínio das técnicas de manejo, planejamento e gestão da atividade.

Palavras-chave: Criação intensiva; Manejo; Curumim; Produção; Comercialização.

\begin{abstract}
The tambaqui (Colossoma macropomum) is a native Amazonian species that presents good zootechnical performance in intensive rearing. The aim of this work was to verify the main aspects related to of $C$. macropomum cultivation in net cages, such as a suitable installation site, ease of handling, uses of feed and the physical, chemical and biological characteristics of the environment, relating to the potential and challenges of the cultivation of this species. For hatchling, a pocket-type nursery is necessary and subsequently pricking out to maintain the homogeneity of the size and weight of the fish. The breeding cycle lasts from 4 to 10 months, depending on the weight of the desired product, being divided into two phases: growing and fattening. The main factors that can enhance the growth of $C$. macropomum during the production cycle are stocking density, food and water quality appropriate, together with the adoption of good sanitary management practices and better control of disease prevention. The "curumim" tambaqui type is the main product sold from net tanks, it is commonly sold in natura, as fresh or frozen fish, has good carcass yield and is well accepted by the collective meals industries. Breeding presents economic risks, as the commercialized prices are close to the production cost. For the success of the activity, skilled labor, specialized technical assistance, rural extension to small producers are necessary to master the techniques of handling, planning and management of the activity.
\end{abstract}

Keywords: Intensive breeding; Management; Curumim; Production; Commercialization. 


\begin{abstract}
Resumen
El tambaqui (Colossoma macropomum) es una especie nativa amazónica que presenta buen desempeño zootécnico en crianza intensiva. El objetivo de este trabajo fue verificar los principales aspectos relacionados com el cultivo de $C$. macropomum en jaula, tales como un lugar de instalación adecuado, facilidad de manejo, usos de los piensos y las características físicas, químicas y biológicas del medio, relacionadas con el potencial y desafíos del cultivo de esta especie. Para las crías, es necesario un vivero tipo bolsillo y posteriormente selección por tamaño para mantener la homogeneidad del tamaño y peso de los peces. El ciclo de crianza tiene una duración de 4 a 10 meses, dependiendo del peso del producto deseado, dividiéndose en dos fases: crecimiento y engorde. Los principales factores que pueden potenciar el crecimiento de C. macropomum durante el ciclo de producción son la densidad de población, la calidad de los alimentos y el agua, junto con la adopción de buenas prácticas de manejo sanitario y un mejor control de la prevención de enfermedades. El tambaqui tipo "curumim" es el principal producto que se vende en las jaulas, comúnmente se vende in natura, como pescado fresco o congelado, tiene un buen rendimiento de carne y es bien aceptado por las industrias alimentarias colectivas. La cría presenta riesgos económicos, ya que los precios comercializados se acercan al costo de producción. Para el éxito de la actividad se requiere mano de obra calificada, asistencia técnica especializada, extensión rural a pequeños productores para dominar las técnicas de manejo, planificación y gestión de la actividad.
\end{abstract}

Palabras clave: Crianza intensiva; Manejo; Curumim; Producción; Comercialización.

\title{
1. Introdução
}

A produção proveniente da piscicultura no Brasil cresceu no ano de 2019, porém, os valores referentes a produção de peixes nativos ficaram estável quando comparado ao ano anterior (Peixe BR, 2020). Isso ocorreu devido a problemas sanitários e estruturais, incluindo processamento e comercialização, além de dificuldades para obtenção de licenciamento ambiental. Os peixes nativos representaram 38\% da produção total da piscicultura no Brasil, sendo o tambaqui (Colossoma macropomum) a espécie de peixe nativo do Brasil mais produzido (Peixe BR, 2020).

O tambaqui, é uma espécie nativa da Amazônia que apresenta bom desempenho em criação intensiva (Val et al., 2000). Seu cultivo na região iniciou-se no começo da década de 1980 (Rolim, 1995; Maeda, 1998). Espécie de hábito alimentar onívoro, em seu ambiente natural alimenta-se preferencialmente de frutos e sementes (Dairiki et al., 2011), apresenta aspectos zootécnicos interessantes ao cultivo, como: aceitação de ração, rusticidade, adaptabilidade ao cativeiro, além de boa qualidade de carne e alto valor comercial. Pode ser criado em diversos sistemas de criação, sendo alguns deles a produção intensiva em viveiros escavados, barragens e tanques-rede, utilizando rações balanceadas de acordo com as características da espécie essencial para o sucesso da produção (Dairiki et al., 2011). Já o estado do Rondônia, proporciona por meio de políticas inovadoras incentivos para que a produção de tambaqui seja ampliada e mais amplamente comercializada, contribuindo, deste modo, para a melhoria da dieta da população e promoção de saúde, por meio do consumo de nutrientes como proteínas, minerais e lipídios que são encontrados na musculatura desses peixes (Dantas Filho et al., 2021).

O território brasileiro apresenta um grande potencial hídrico, estima-se em 5,3 milhões de hectares de água doce represada em grandes reservatórios naturais e artificiais, somando a condições climáticas favoráveis e disponibilidade de alimentos completos para piscicultura intensiva (Sidonio et al., 2012). A criação de peixes em tanques-rede é um sistema de criação intensiva, Signor et al. (2020) destacam que essa tecnologia exige maior conhecimento técnico do produtor, rações mais bem elaboradas, manejos tecnológicos específicos, ou seja, maiores custos, no entanto a produtividade é bem superior, e consequentemente se bem conduzida pelo produtor trará maior lucratividade. A criação de peixes em tanques-rede apresenta vantagens econômicas de investimentos iniciais, sendo de 60 a 70\% menor se comparado à criação em viveiros escavado (Furlaneto et al., 2006). Neste sentido, o objetivo do presente trabalho é demostrar os principais aspectos técnicos da criação de tambaqui (C. macropomum) em tanques-rede. 


\section{Metodologia}

O estudo trata-se de uma revisão bibliográfica de natureza qualitativa, com característica exploratória como preconizado por Pereira et al. (2018), constituída por artigos selecionados aos assuntos abordados (tanques-rede; qualidade de água; densidade de estocagem; alevinagem; repicagem; engorda/terminação; capacidade de suporte em tanques-rede; nutrição e manejos alimentares; sanidade; mercado e comercialização e viabilidade econômica).

O levantamento de informações foi realizado por meio de buscas realizadas nos bancos de dados nacionais e internacionais, como: National Library of Medicine (PUBMED), Scientific Electronic Library Online (SCIELO), além da ferramenta do Google Acadêmico, bem como livros, teses e dissertações gratuitos disponíveis na web, que encontram em formato completo, além de manuais técnicos da Empresa Brasileira de Pesquisa Agropecuária (EMBRAPA) e da Companhia de Desenvolvimento dos Vales do São Francisco e do Parnaíba (CODEVASF), que contemplam os aspectos técnicos do cultivo de tambaqui em tanques-rede. O período das buscas foi entre os meses de novembro de 2020 a junho de 2021. Em relação ao ano de publicação dos trabalhos técnicos utilizados não foi delimitado um período.

\section{Resultados}

\section{Tanques-rede}

A criação de peixes em tanques-rede vem sendo uma modalidade amplamente difundida no Brasil, mostrando-se uma técnica promissora por possibilitar a ocupação sustentável do meio ambiente com uma elevada produtividade e densidade de estocagem (Liranço 2011; Santos et al., 2018), e por isso, exige constante renovação de água para a dispersão dos resíduos metabólicos dos peixes no ambiente (Mallasen et al., 2011). Essa tecnologia propicia maior rapidez de implantação e o aproveitamento racional de corpos hídricos já existentes (mar, rios, grandes reservatórios, açudes, canais de irrigação, entre outros), que não podem ser explorados com o cultivo dos peixes soltos, acarretando uma rápida expansão industrial no país, com produção em grande escala, em curto período (Campos et al., 2007; Sabaini et al., 2015).

Tanques-rede são estruturas flutuantes para criação de peixes, constituídas por redes em diversas formas e tamanhos, com a função de reter um determinado número de indivíduos, permitindo livre fluxo de água (Taniguchi et al., 2014). Podendo apresentar diversas formas no mercado, sendo as principais: quadrangulares, retangulares e circulares. Atualmente, em projetos para produção de peixes em tanque-redes continentais com espécies de água doce, o formato mais utilizado é o quadrangular (Rotta \& Queiroz, 2013), principalmente pelo fácil manejo nas estruturas e, pela troca de água.

\section{Seleção do Local de Instalação}

A escolha do local para a instalação de tanques-rede é preciso levar em consideração alguns fatores, segundo AguilarManjarrez e Ross (1995), Moccia e Reid (2007), Halide et al. (2009) e Codevasf (2019), tais como:

- Áreas com conflitos de interesse ou com outras atividades, como pesca, turismo e navegação, devem ser criteriosamente analisadas ou até mesmo evitadas;

- A segurança do local dos tanques contra furtos é um fator a ser criteriosamente analisado;

- Também deve-se levar em consideração na escolha do local, o estudo da viabilidade técnica e econômica da atividade, bem como o planejamento estratégico de produção, considerando os seguintes requisitos:

a) tipo de produto e preço de comercialização (atacado e/ou varejo);

b) quantidade demandada pelo mercado;

c) ciclo de cultivo e escala de produção;

d) proximidade com o mercado consumidor (logística de escoamento da produção); 
e) capital de investimento e operacional (fonte de recursos);

f) mão de obra qualificada (treinada).

A criação de peixes em tanques-rede exige que a água, onde se pretende instalar, seja de boa qualidade. Isso depende de características físicas, químicas e biológicas do ambiente, como: temperatura, concentração de oxigênio dissolvido, pH, turbidez, grau de eutrofização, entre outros fatores, que seja adequada a espécie de cultivo.

Assim, é recomendado evitar ambientes eutrofizados, que provocam grande variação diária na qualidade da água. O ideal é que sejam locais de baixa atividade primária (planctônica), alta transparência da água (acima de $2 \mathrm{~m}$ ) e com menores variações diárias nos parâmetros físicos e químicos da água, principalmente na temperatura da água (Moro et al., 2013). É muito importante que os parâmetros de qualidade de água devem ser aceitáveis para a espécie C. macropomum e é preciso evitar áreas corpos de água que possam receber efluentes industriais ou domésticos pois a água pode carregar contaminantes que pode ser absorvido pelos peixes e causar transtorno ao consumidor final.

Aspectos climáticos devem ser levados em consideração para os peixes criados terem um ótimo desempenho. Selecionar áreas protegidas de corredores de ventos e da água. Locais com ambientes estáveis, com uma boa dinâmica de água que não possua ondas ou marolas, são indicados para instalação de uma piscicultura de tanques-rede.

Se o local selecionado não possuir as descrições anteriores, influenciará no potencial de crescimento dos peixes durante o ciclo de produção, principalmente quanto a qualidade da água (Mallasen,et al., 2018), ganho de peso e a conversão alimentar (Brandão et al., 2004).

\section{Qualidade de água}

As condições de qualidade da água são determinadas por inúmeros processos químicos, físicos e biológicos, que interferem de forma individual ou coletiva na produção de peixes. Quando inadequada, pode causar prejuízos no crescimento, na reprodução, na saúde, na sobrevivência e na qualidade dos peixes, que compromete o sucesso dos sistemas produtivos do pescado (Kubitza, 1998; Américo et al., 2012).

A criação do tambaqui em tanques-rede é uma opção sustentável para a produção de pescado em reservatórios de hidrelétricas e açudes que são destinados a captação de água pluvial para consumo doméstico, irrigação e dessedentação animal, integrandos os usos múltiplos se necessidade de drenagem para executar a despesca (Silva, 2015). Além disso, é importante conhecer o impacto do sistema de produção de peixes em tanques-rede sobre a qualidade da água do ambiente para atender o multiuso e garantir assim, a sustentabilidade (Silva \& Fujimoto, 2015).

A água é o recurso mais importante nos sistemas de produção de tambaquis em tanques-rede e sua qualidade está relacionada a diversos fatores, como: procedência, práticas de manejo durante a criação, quantidade e composição da ração ofertada aos peixes. Ela deverá ter uma composição física e química adequada para a criação de tambaquis. Os fatores químicos e físicos que geralmente são analisados é a temperatura, $\mathrm{pH}$, transferência, compostos nitrogenados e gases dissolvidos, como oxigênio e gás carbônico (Silva \& Fujimoto, 2015; Tavares-Dias et al., 2018).

A princípio, o parâmetro mais importante a ser monitorado é o nível de oxigênio dissolvido que deve ser geralmente alto em todas as épocas do ano, necessitando do seu monitoramento em dois períodos do dia, pela manhã e à tarde, entre $15 \mathrm{~h} \mathrm{e}$ 16h (Américo et al., 2012; Tavares-Dias et al., 2018). Outro critério importante para a criação de tambaqui é a boa renovação de água no ambiente de instalação da piscicultura de tanque-rede, para que assim as correntes e o fluxo de água sejam suficientes para evitar o acúmulo de fezes e restos de ração nas proximidades e embaixo dos tanques, reduzindo os níveis de oxigênio dissolvido pela degradação da matéria orgânica acumulada.

A eutrofização é outro fenômeno que deve ser avaliado na qualidade de água no sistema de produção de tambaquis em tanques-rede, pois se refere ao aumento da carga orgânica no sedimento abaixo dos tanques-rede e o aumento do nitrogênio e 
fósforo total nos sedimentos e água intersticial (Karakassis et al., 2000; La Rosa et al., 2004). Para tal avaliação, o uso do disco de Secchi verifica a transparência da água e valores devem estar entre 60 a $200 \mathrm{~cm}$ para serem considerados bons para o cultivo de peixes em tanques rede.

As alterações na qualidade da água causadas pelo crescimento de cianobactérias podem acarretar prejuízos no cultivo, principalmente porque esses microrganismos são produtores de toxinas e de compostos odoríferos trans-1,10-dimetil-trans-9decalol (geosmina) e 2-metilisoborneol, os quais conferem odor e sabor de terra e mofo à água (Young et al., 1996; Zat \& Benetti, 2011). Nos peixes os compostos odoríferos ocasionam o sabor de barro ou lama, ocorrência conhecida por off-flavor, que prejudica o valor do pescado para sua comercialização.

Estudos avaliando a qualidade da água em sistemas de cultivo de peixes em tanques-rede com tambaquis tem sido mais frequente. Silva e Fujimoto (2015) avaliando o crescimento do tambaqui em diferentes densidades de estocagem em tanques-rede em lago abastecido com água de chuva e seus efeitos sobre a qualidade ambiental, observou que houve alterações no nitrogênio e fósforo, além disso, o aumento dos teores de matéria orgânica, nitrogênio e fósforo foram verificados no sedimento abaixo dos tanques-rede, sem causar eventos de eutrofização, concluindo que é possível cultivar tambaquis em lagos abastecidos com água de chuva, integrando os preceitos de usos múltiplos da água.

Santos e Silva (2017) monitoraram os parâmetros de qualidade da água como temperatura, pH, oxigênio dissolvido, entre outros, ao longo do período de engorda do tambaqui (Colossoma macropomum) em sistema de criação semi-intensiva em tanques-rede em lago de 0,5 ha da Embrapa Tabuleiros Costeiros em Aracaju, SE, e avaliaram que esses parâmetros monitorados enquadram-se nos padrões da classe 2 destinadas à aquicultura (Resolução n 357 - Conama), e os valores da temperatura, oxigênio dissolvido e pH da água encontram-se dentro dos limites recomendados para a criação do tambaqui. Segundo Boyd e Tucker (1998) e Codevasf (2019), o crescimento ótimo para peixes em tanque-rede encontra-se com temperatura entre 26 a $30^{\circ} \mathrm{C}$, oxigênio dissolvido entre 5-8 mg/l, pH numa faixa de 6,5 a 8,5, transparência entre 60 a $160 \mathrm{~cm}$ e sem presença de amônia e nitrito.

Nesse sentido, é necessário haver um constante monitoramento da qualidade da água, não apenas dentro e entre os tanques-rede, mas também no ambiente que envolve a atividade para que haja uma garantia da qualidade do produto bem como da sustentabilidade dos sistemas intensivos de produção de peixes (Marengoni, 2006; Américo et al., 2012).

\section{Densidade de Estocagem}

A densidade de estocagem é a quantidade máxima de peixes produzidos, por unidade de volume $\left(\mathrm{m}^{3}\right)$, até atingir o peso de despesca. A biomassa de peixe dos tanques, irá depender do tamanho (alevinos, juvenis e adultos) dos peixes que serão estocados e o peso final a serem despescados (Salaro \& Lambertucci, 2011). Conhecer a densidade de estocagem é fundamental para garantir o sucesso da produção de peixes de qualquer espécie em tanques-rede, pois trará informações sobre os níveis ótimos de produtividade que podem ser atingidos (Brandão et al., 2004; Frasca-Scorvo et al., 2011) nas diferentes fases de cultivo, influenciando na sobrevivência e no crescimento (Jobling, 1994).

Sendo assim, a determinação da densidade de estocagem adequada é essencial para o máximo aproveitamento do espaço do tanque ocupado pelos peixes, otimizando os custos de produção em relação ao capital investido (Ayrosa et al., 2011). O cálculo da densidade de estocagem é feito da seguinte forma: Densidade de estocagem $\left(\right.$ peixes $\left./ \mathrm{m}^{3}\right)$ final $=$ Biomassa recomendada/peso desejado na despesca.

Exemplo: biomassa recomendada de $35 \mathrm{~kg} / \mathrm{m}^{3}$

Peso de despesca tambaquis de $1,1 \mathrm{~kg}$

Densidade de estocagem $=35 \mathrm{~kg} / \mathrm{m}^{3} / 1,1 \mathrm{~kg}$

Densidade de estocagem $=31,8$ peixes $/ \mathrm{m}^{3}$ 
Avaliando o cultivo em fase experimental, Chellapa et al. (1995) obtiveram uma produção de $14,4 \mathrm{~kg} / \mathrm{m}^{3}$ na densidade de 34 peixes $/ \mathrm{m}^{3}$. Brandão et al. (2004) determinaram a densidade de estocagem mais adequada para a fase de recria de juvenis de tambaqui (C. macropomum) em tanque-redes e concluíram que a produção por área em tanque-rede é maior com o aumento da densidade de estocagem e que a densidade de estocagem ideal para fase de recria de tambaqui em tanque-rede é de 400 peixes $/ \mathrm{m}^{3}$. Ferraz (2004) e Gomes et al. (2006) obtiveram valores muitos próximos aos encontrados no lago Tupé com tambaqui em tanques rede em lagos de várzea amazônico. Freitas (2009) encontrou resultados de desempenho zootécnico positivos na densidade de 90 peixes $/ \mathrm{m}^{3}$, onde atingiram $547,83 \pm 28,47 \mathrm{~g}$ de peso médio, sobrevivência de $99,4 \pm 0,11$ e conversão alimentar de 1,45 0,08 no período de 9 meses. Silva e Fujimoto (2015) avaliaram o crescimento do tambaqui em diferentes densidades de estocagem em tanques-rede em lago abastecido com água de chuva e seus efeitos sobre a qualidade ambiental e verificaram que a densidade de 20 juvenis $\mathrm{m}^{-3}$ é a mais adequada para a terminação de tambaquis em tanques-rede, demonstrando que a criação de tambaquis em tanques-rede é viável em lagos abastecidos com água de chuva e pode integrar-se aos preceitos dos usos múltiplos da água. Assim, podemos concluir que a densidade de estocagem é um fator crítico que deve ser considerado na produção final devido à influência na sobrevivência, crescimento dos peixes, produção e qualidade da água (Rowland, 2006; Oliveira et al., 2012; Silva \& Fujimoto, 2015).

\section{Alevinagem}

A alevinagem de tambaqui em tanques-rede é realizada utilizando berçários, pois os peixes apresentam de $1 \mathrm{a} 3 \mathrm{~cm}$. Os berçários, são tanques constituídos com redes em nylon multifilamento sem nó (tipo bolsão), que são instalados dentro do tanque-rede de tela metálica plastificada ou aço inoxidável. Recomenda-se que a abertura do berçário seja de $5 \mathrm{~mm}$. De acordo com Silva e Fujimoto (2015), a densidade estocagem recomendada para a alevinagem de tambaqui é de 300 alevinos $/ \mathrm{m}^{3}$.

O teor de oxigênio dissolvido deve ser superior a $3 \mathrm{mg} / \mathrm{L}$, o $\mathrm{pH}$ deve estar próximo a 7 e a temperatura acima de $28^{\circ} \mathrm{C}$ (Gomes et al., 2010; Mendonça et al., 2012) na fase de alevinagem. De acordo com Lima et al. (2016) a melhor teor de proteína bruta na ração para alevinos de 0,35 a $15,11 \mathrm{~g}$ é de $31,57 \%$.

Alguns piscicultores realizam essa etapa em viveiros escavados devido a fragilidade dos peixes e por ser um ambiente em que é possível manter a qualidade de água aceitável para a espécie. Atualmente, existem disponíveis no mercado alevinos de tambaqui de origem do programa de melhoramento genético iniciado no Projeto AquaBrasil, rede de pesquisa que reuniu unidades da Embrapa, universidades e instituições de pesquisa, empresas privadas e estaduais (Resende, 2009). Estes peixes melhorados geneticamente, foram selecionados para um maior ganho de peso diário, sendo $14,8 \%$ superior quando comparados com peixes que não foram melhorados (Marcos et al., 2016).

\section{Repicagem}

A repicagem é a transferência dos peixes de diferentes tamanhos alojados em um tanque para outros tanques-rede (Nascimento, 2007). Durante a repicagem é realizada a classificação em lotes de mesmo tamanho/peso. Essa prática deve ser realizada por meio de classificadores (telas ou barras paralelas) ou em mesa classificadora na balsa de manejo. A padronização em lotes de tamanho/peso propicia diminuir/reduzir/anular temporariamente o efeito da dominância estabelecido no lote, produzindo lotes mais homogêneos de peixes. Deve ser realizada nos horários com temperaturas mais amenas (início do dia), evitando o estresse dos animais. Assim como em biometrias, antes de capturar os peixes, é indicado um dia de jejum.

Durante a criação, são realizadas duas repicagens, sendo a primeira no término da fase de recria quando os alevinos atingem 5 a $8 \mathrm{~cm}$ e são retirados da tela de berçário, a segunda repicagem ocorre no início da fase de engorda com cerca de 60 dias quando juvenis estão com 10 a $12 \mathrm{~cm}$, podendo haver uma terceira repicagem por faixa de comprimento dos peixes em pequeno, médio e grande durante a fase terminação, antes da despesca (Oliveira et al., 2011). 
De acordo Oliveira et al. (2009), os índices zootécnicos do ciclo de produção, no qual passou por repicagem, foram otimizados em relação ao ciclo anterior no mesmo período do ano anterior. Assim recomenda-se a realização da repicagem e que é uma técnica implementada com sucesso no cultivo de tambaqui em tanques-rede.

\section{Engorda/Terminação}

É o período final da criação de peixes em tanques rede, também conhecido como engorda, onde os peixes são mantidos até atingirem o peso comercial. Durante essa etapa, os tambaquis são alimentados com ração $22 \%$ obtiveram o mesmo resultado no desempenho quando comparados com tambaquis alimentados com ração $28 \%$ de proteína bruta, sendo economicamente mais viável alimentar com ração com $22 \%$ (Neto et al., 2017). Para o tambaqui, em terminação com a densidade final de 20 peixes $/ \mathrm{m}^{3}$, é atingir o peso corporal de 1,0 kg, em 9 meses de criação (Codevasf, 2019).

A taxa de alimentação deve ser próxima de 3 a 1\% do peso vivo dos peixes, diminuindo do início para o final do cultivo. Recomenda-se estar sempre atento ao comportamento dos peixes durante a alimentação afim de evitar sobras e/ou suspender a oferta de ração quando os níveis de oxigênio dissolvido na água forem menores que $2 \mathrm{mg} / \mathrm{L}$. Em tanques-rede o tambaqui pode atingir $950 \mathrm{~g}$ em 240 dias de criação, com uma conversão alimentar de 1,8 e produção de 46,8 kg/ha (Gomes et al., 2006).

\section{Capacidade de Suporte dos tanques-rede}

A capacidade de suporte do tanque está relacionada a capacidade de renovação total do volume de água, ou seja, quanto maior for o tanque-rede, menor é capacidade de suporte do tanque por metro cúbico, porém, terá uma capacidade de produzir um volume maior de peixes.

Normalmente, os tanques-rede mais recomendados são os quadrados e circulares quando o volume é acima de $100 \mathrm{~m}^{3}$. Os quadrados são recomendados por apresentarem maior taxa de renovação da água quando comparados aos tanques-rede circulares. Devido ao fato de que os tanques-rede quadrados apresentam maior área lateral. Além disso, o produtor tem a opção de posicionar os tanques-rede de forma que a correnteza ou movimento da água favoreça a renovação de água.

Para tanques-rede de grande volume (acima de $100 \mathrm{~m}^{3}$ ) os tanques circulares se apresentam com boas opções de cultivo, contudo, os manejos empregados nos cultivos são diferentes e exigem estruturas de apoio a cultivo próprias, como manejos de despesca, repicagem e outros.

\section{Nutrição e Manejo alimentares}

Em ecossistemas aquáticos naturais, a alimentação do tambaqui é baseada preferencialmente em frutos e sementes no período de enchente e cheia dos rios, porém, em épocas de vazante e seca, ele consome principalmente zooplâncton, tendo como hábito alimentar comumente definido como onívoro-oportunista (Honda, 1974; Goulding \& Carvalho, 1982). Segundo estes autores, outros itens alimentares como macrófitas, insetos, algas, moluscos e peixes também são consumidos pela espécie, mas em menor frequência e muitas vezes ingeridos acidentalmente com os alimentos principais.

Em sistema de tanques-rede, o ciclo de criação de tambaqui dura de 9 a 10 meses, sendo dividido em duas fases: recria e terminação. Existem diversos fatores que podem influenciar no potencial de crescimento de tambaquis em uma piscicultura de tanque-rede durante o ciclo de produção, entre esses, a densidade de estocagem, a alimentação e a baixa qualidade da água (Tavares-Dias et al., 2018).

Para estabelecer estratégias eficientes de manejo alimentar, deve-se avaliar a taxa e frequência de alimentação, além de métodos adequados de dispersão do alimento (Goddard, 1996). Segundo Eroldogan et al. (2004) e Chagas et al. (2007) a taxa de alimentação e eficiência alimentar são fatores que mais influenciam no crescimento de peixes cultivados, e o seu 
crescimento é diretamente proporcional à taxa de arraçoamento empregada. A adoção de estratégias de alimentação adequadas, nas diferentes fases de vida dos peixes, permite não só melhorar o seu crescimento, mas também a sua sobrevivência e conversão alimentar, contribuindo para reduzir o desperdício de ração, o que prejudica a qualidade da água de cultivo e a produção (Goddard, 1996).

As estratégias de alimentação adequadas devem considerar o equilíbrio entre eficiência de utilização do alimento e maximização do crescimento, o que implica no uso de taxas de alimentação restritas e fixas em alternativa à alimentação até a saciedade aparente (Van Der Meer et al., 1997; Rodrigues, 2014). Assim sendo, a relação energia/proteína e a disponibilidade de nutrientes devem ser adequadas às exigências da espécie para que apresentem boas taxas de crescimento (Hayashi et al., 2002).

A maioria dos estudos existentes sobre exigências nutricionais do tambaqui foram realizados com dietas práticas, ao invés de dietas purificadas ou semi purificadas, dificultando a interpretação dos resultados pela interação entre os nutrientes dos ingredientes (Fracalossi et al., 2012). Que pode estar relacionado a complexidade existente no manejo e a complexidade e a avaliação de larvas, associado a custos e ao manejo de peixes maiores e elevado custo de reprodutores. Os ingredientes práticos apresentam coeficientes de digestibilidade variáveis, que geralmente que dificulta a comparação entre trabalhos. Além disso, existe uma carência de estudos com animais na fase intermediária e final de engorda e com reprodutores e larvas, havendo uma concentração de estudos com tambaquis entre 1 e $100 \mathrm{~g}$ (Rodrigues, 2014). Chagas et al. (2005) avaliaram o efeito da taxa de alimentação $(5,7,5$ e $10 \%)$ do peso vivo dia $^{-1}$, sobre o desempenho e parâmetros metabólicos de tambaqui cultivado em tanques rede, perceberam que o fornecimento de ração para juvenis de tambaqui, na taxa de $5 \%$ do peso vivo dia

${ }^{1}$, sob condições de lagos de várzea, permite um desempenho aceitável da espécie.

Em outro trabalho, Chagas et al., (2007) avaliando o efeito da taxa de alimentação sobre a produtividade e os níveis de glicose sanguínea, proteínas totais e triglicérides plasmáticos de juvenis de tambaqui criados em tanque-rede tiveram resultados bastante satisfatórios considerando que não ocorreu alteração significativa nos níveis de glicose sanguínea, triglicérides e proteínas plasmáticas de tambaquis submetidos aos diferentes tratamentos e que taxa de alimentação adequada para a produtividade de juvenis de tambaqui criados em tanques-rede instalados em lagos de várzea, pesando inicialmente $200 \mathrm{~g}$, é de $1 \%$ do peso vivo dia $^{-1}$.

Oliveira et al. (2020) caracterizaram o valor nutricional e rendimento de tambaquis em duas classes de tamanho: curumim $(0,350 \mathrm{~kg}$ e 0,450$) \mathrm{kg}$ e tamanho comercial $(1 \mathrm{a} 3 \mathrm{~kg})$, provenientes de tanques-rede, e concluiu que o tambaqui curumim apresentou valor nutricional adequado e melhor rendimento em relação ao tamanho comercial e que a inserção do tambaqui tipo curumim nas dietas dependerá da aceitação pelos mercados onde sua comercialização não esteja estabelecida.

Percebe-se que há uma carência de estudos de exigências nutricionais e manejo alimentar com animais na fase intermediária e final de engorda. E com reprodutores e larvas, havendo uma concentração de estudos com tambaquis entre $1 \mathrm{e}$ $100 \mathrm{~g}$. Visto que a maioria dos alimentos testados para a espécie apresenta disponibilidade restritamente local e volume de produção insuficiente para sua incorporação pelas indústrias de ração, e faz necessária a avaliação de ingredientes com maior potencial de utilização para a alimentação do tambaqui e pesquisas que investiguem a digestibilidade dos mesmos em sistemas de criação em tanques-rede (Rodrigues, 2014).

\section{Sanidade}

As condições sanitárias da piscicultura de tambaqui em tanques-rede são bastante relevantes para o desenvolvimento da produção. Assim, técnicas profiláticas e manejo sanitário adequado devem ser usados para melhorias na produção nesse sistema intensivo. Investigações devem ser conduzidas frequentemente no sentido de verificar a possível entrada de patógenos nos tanques-rede (Tavares-Dias et al., 2013). A ocorrência de infecções parasitárias é um fator determinante para o sucesso da 
piscicultura de qualquer espécie de peixe, principalmente em tanque-rede. Assim, nessa modalidade de piscicultura intensiva, a sanidade é um dos aspectos que não podem ser jamais negligenciados (Santos et al., 2013).

Além disso, muitas doenças apresentam sinais clínicos evidentes pelas alterações na superfície externa dos peixes, tais como: ulcerações, congestão, despigmentação/pigmentação, deformação do esqueleto, irregularidades nas nadadeiras, entre outras. Esses sinais clínicos podem auxiliar no diagnóstico parasitológico e as mudanças comportamentais podem ser observadas. Peixes doentes tendem não ir em busca do alimento, neste caso se for observada anorexia em apenas alguns indivíduos e associada à letargia, poderá ser indicativo de doença (Ramos, 2006; Tavares-Dias et al., 2013).

Um estudo avaliando a parasitofauna de tambaquis cultivados em tanques-rede instalados no Rio Matapi, município de Santana, estado do Amapá, Brasil, dos quais dos 60 tambaquis analisados, 96,7\% estavam parasitados por protozoários Ichthyophthirius multifiliis (Ciliophora) e Piscinoodinium pillulare (Dinoflagellida), monogenoideas Mymarotheciun boegeri e Anacanthorus spathulatus (Dactylogyridae) e sanguessugas Glossiiphonidae gen. sp. (Hirudinea) (Santos et al., 2013). Uma das variáveis que deve ser cogitada nos estudos de parasitas em peixes é o fator de condição, pois se trata um indicador quantitativo do grau de bem-estar dos peixes que pode ser usado para avaliar os efeitos do parasitismo na saúde dos hospedeiros (Lemos et al., 2007; Guidelli et al., 2011).

Os protozoários são o parasito mais comum em peixes de cultivo e responsável por perdas econômicas significativas em pisciculturas de todos os continentes (Tavares-Dias et al., 2001; Lemos et al., 2007; Pavanelli et al., 2008; Eiras et al., 2010). Eles verificaram que são necessários estudos adicionais conduzidos durante todas as fases do cultivo e nas diferentes densidades de estocagem usualmente praticadas em pisciculturas de tanque-rede.

O melhor controle das doenças é a prevenção com a adoção de boas práticas de manejo sanitário durante a larvicultura e alevinagem do tambaqui, evitando a sua introdução nos sistemas de cultivo. Sendo assim, é necessário usar peixes livres de patógenos, realizar quarentena e eliminar as larvas e alevinos com qualquer sinal de doenças e, além disso, realizar tratamento profilático quando adquirir peixes de outras propriedades (Affonso et al., 2009).

\section{Mercado e comercialização}

Vários fatores devem ser considerados para que ocorra o sucesso na criação em tanques-rede, entre eles a instalação, manejo e mercado (Ono \& Kubitza, 2003). Segundo Brandão et al. (2004), é importante observar o crescimento dos peixes, pois a homogeneidade dos peixes no momento da despesca influência na comercialização.

Criações de tambaqui C. macropomum em tanques-rede instalados em lagos de várzea da Amazônia Central têm alcançado alta produtividade, sendo apontadas como uma atividade promissora entre as populações ribeirinhas da Amazônia (Chagas et al., 2007), pois apresenta alto valor comercial e é muito apreciado na região Amazônica (Menezes et al., 2008). Esse peixe tem grande destaque na piscicultura continental em todo o Brasil, sendo a principal espécie nativa cultivada no país (Lobo et al., 2015), possui um amplo mercado e é bem aceito nacionalmente (Pedroza Filho et al., 2016), com uma produção anual de 101,1 mil toneladas (IBGE, 2020).

O tambaqui é comumente comercializado in natura, como peixe fresco ou congelado (Oliveira et al., 2019). Em peixes menores, é usada a técnica de "ticar", que são vários cortes paralelos feitos na transversal à coluna vertebral como objetivo de quebrar as espinhas para facilitar o consumo (Feio, 2015). Pois, um dos principais problemas no processamento é a presença de espinhos intramusculares em forma de "Y" (Perazza et al., 2016). Em mercados, feiras e supermercados, o consumidor pode adquirir tambaqui desossado com a retirada da espinha na hora da compra (Feio, 2015) e do filé pode transformá-lo em surimi para agregar valor ao produto (Damasceno et al., 2014). No beneficiamento, o tambaqui apresenta rendimento total de carcaça de $63,71 \%$ em peixes com média de $40,23 \mathrm{~cm}$ e com peso médio de $1,54 \mathrm{~kg}$ (Cartonilho \& Jesus, 2011). 
Quanto a cortes congelados de tambaqui, se mantem em bom estado de conservação por até 180 dias a $-25{ }^{\circ} \mathrm{C}$ (Cartonilho \& Jesus, 2011). A comercialização do produto a vácuo também é uma excelente alternativa para a inserção no mercado, pois aumenta a vida de prateleira do produto (Ramos et al., 2016).

O tambaqui tipo "curumim" é o principal produto de comercialização oriundos de tanques-rede na Amazônia (Costa et al., 2017), é o próprio tambaqui cultivado de maneira intensiva ou superintensiva e comercializado ainda na sua fase juvenil (Filho, 2001), resultado da criação em confinamento, por 4 a 6 meses, atingindo peso de 350 a 450 g (Franco et al., 2013). Devido ao ciclo produtivo de menor duração, ele se caracteriza como uma opção de retorno rápido (Granda, 2010). Surgiu inicialmente como alternativa de mercado, para suprir a escassez de espécies de pequeno porte como o pacu (Milossoma spp.) e jaraqui (Semaprochilodus spp.) na entressafra e possui boa aceitação pelas indústrias de refeições coletivas (Costa et al., 2017). Por conta do seu sabor e do tamanho adequado para uma refeição, vem ganhando o mercado consumidor (Tavares-Dias et al., 2018), com melhor qualidade organoléptica em relação ao cultivo em viveiros (Ayrosa et al., 2005). A elevada demanda por tambaqui curumim favorece o surgimento de novos produtores e o crescimento daqueles já instalados. Entretanto, este é um mercado ainda escasso de informações que possibilitem os produtores tomarem decisões assertivas e que diminuam possíveis vulnerabilidades mercadológicas (Costa et al., 2017).

Na região norte, Manaus é principal mercado consumidor de tambaqui e uns dos principais polos geradores e fornecedores de tecnologia e insumos (Morais \& O'sullivan, 2017). O consumo anual de tambaqui oriundo de piscicultura é de 40.000 toneladas, correspondendo a um consumo per capita anual de $17 \mathrm{~kg} / \mathrm{habitante}$ (Costa et al., 2017). Este mercado aumentou com a instalação do Polo Industrial de Manaus, que intensificou a migração da população do interior para capital e aumentou a demanda pelo pescado (Gandra, 2010).

Em criações próximo a Manaus (AM), no lago do Puraquerara, tambaquis atingiram 337g em um período de 4 meses na densidade utilizando 70 peixes $/ \mathrm{m}^{3}$. Oliveira et al. (2011) acompanhando engorda no período de 4 meses no lago do Tupé, observaram que tambaquis foram comercializados com 378,41 $\pm 23,03 \mathrm{~g}$ em média. Já no lago do Limão, obteve um peso final de $410 \mathrm{~g}, 391 \mathrm{~g}$ e $402 \mathrm{~g}$ nas densidades de estocagem de 20, 30, 40 peixes $/ \mathrm{m}^{3}$ respectivamente, durante um período de 5 meses (Ferraz, 2004).

Criação de tambaqui em tanques-rede também tem crescido como alternativa para comunidades indígenas (Prochmann \& Tredezini, 2002) e ribeirinhos da agricultura familiar (Oliveira et al., 2011), implantados como alternativa produtiva para geração de renda, trabalho, alimento e melhoria da qualidade de vida. De acordo com esses autores, a piscicultura é uma atividade que parece difundir-se com maior facilidade entre produtores rurais, principalmente em pequenas propriedades.

A despesca ou retirada dos peixes dos tanques-rede pode ser parcial ou total e deve ser com mínimo possível de estresse (Tavares-Dias et al., 2018). Quando a captura é parcial, utiliza-se um puçá para fazer a retirada dos peixes (Ono \& Kubitza, 2003). O ideal para o produtor é pesar e anotar toda e qualquer quantidade de tambaqui retirado (kg). Para o abate, um dos métodos de insensibilização utilizado é a hipotermia, que consiste na exposição dos peixes as baixas temperaturas utilizando gelo e água na proporção 1:1 para redução do metabolismo do animal, garantindo que não sentirão dor durante o abate, devendo ser rápida, eficaz e corroborar com as diretrizes nacionais para o bem-estar dos peixes (Fogaça et al., 2018). Segundo este autor, o consumo do pescado permanece seguro e com características sensoriais, químicas, físicas e microbiológicas desejáveis (IFST, 1993), pois o intervalo de tempo entre a despesca, o abate e a comercialização do produto devem ser relativamente curtos.

Quanto à comercialização do peixe, Pedrazzani (2007), nos diz que é de extrema relevância que o produtor possua a ciência de que estar inserido dentro de uma cadeia de produção, tendo que desta forma, estar voltado para os anseios do 
mercado consumidor local e regional, com o foco de comercializar a produção, dando grande importância a divulgação, aliada a uma eficiente e otimizada logística de distribuição do pescado.

\section{Viabilidade econômica}

A viabilidade de empreendimentos aquícola está diretamente relacionada ao manejo adequado e bom gerenciamento da atividade (Freitas, 2011). Portanto, a falta de indicadores econômicos gera muita incerteza para o desenvolvimento desta atividade (Carneiro et al., 1999). Os aspectos econômicos são importantes no planejamento, no controle e na tomada de decisões de uma piscicultura (Coelho \& Cyrino, 2006; Brabo et al., 2013). Segundo Ayroza (2009), a utilização de critérios técnicos no manejo de peixes em tanques-rede pode-se obter o incremento da produção aquícola, atração de novos investidores e tornando a atividade excelente alternativa de geração de empregos e renda, além de ajudar na conservação da espécie para diminuir a pressão sobre os estoques pesqueiros naturais e as várzeas.

Acerca do crescente desenvolvimento da criação de tambaqui na região norte do país, é necessário conhecer todos os aspectos econômicos que envolvem esta atividade em tanques-rede, classificando os itens do custo de produção e os principais critérios que influenciam na rentabilidade, verificando a viabilidade econômica e identificar as possíveis causas de desistências (Brabo et al., 2013). Assim, essas análises têm sido amplamente utilizadas como ferramenta gerencial na piscicultura para mostrar viabilidade de sistemas de criação (Campos et al., 2007), possibilita observar o comportamento de um empreendimento frente ao mercado (Silva et al., 2012; Furlaneto et al., 2010), maior poder de negociação e segurança para o desenvolvimento de novos ciclos de produção e para futuros empreendedores (Leonardo et al., 2012).

Segundo Freitas (2009), o investimento para a implantação de um módulo de produção familiar com 12 tanques com $6 \mathrm{~m}^{3}$ foi $64,5 \%$. A participação da ração e alevinos na formação dos custos totais variou entre $48 \%$ e $55 \%$ do custo total para as densidades de 50 e 90 peixes $/ \mathrm{m}^{3}$. O custo unitário de produção de tambaqui em tanque-rede apresentou de $\mathrm{R} \$ 4,93 / \mathrm{Kg}, \mathrm{R} \$$ $4,54 / \mathrm{Kg}$ e $\mathrm{R} \$ 3,65 / \mathrm{Kg}$ para as densidades de 50,70 e 90 peixes $/ \mathrm{m}^{3}$ respectivamente, sendo acima de $45 \%$ do custo total de produção. Em tanques-rede, a participação da ração na formação do custo total pode ser ainda maior, tendo em vista que esta é a única fonte de alimento dos animais (Scorvo-Filho et al., 2006). Assim, o cultivo de tambaqui curumim na região do Tupé (AM) não obteve viabilidade econômica.

Projetos comunitários de tanques-rede demonstram a dependência de políticas públicas nessa modalidade para se manter como uma atividade produtiva para a geração de renda (Oliveira et al., 2011). Os resultados econômicos obtidos pelos autores foram de lucro de $\mathrm{R} \$ 1.285,00$ por família durante o ciclo, mostrando que a sustentabilidade de unidade familiar de produção depende diretamente da capacidade de produção instalada e da ajuda solidária para o custeio no total ou em parte dos custos de produção.

Gomes et al. (2006), avaliando quatro densidades de estocagens (20, 30, 40 e 50 peixes.m-3 $\left.{ }^{3}\right)$ no cultivo de tambaqui em tanques-rede no lago Ariauzinho (Iranduba-AM), observaram que os custos de produção e a renda líquida foram diretamente relacionados com a densidade de estocagem. Entretanto, somente a maior densidade apresentou índices econômicos positivos, com participação de $88,1 \%$ (custo fixo) e 11,9\% (custo variável no custo total). Esses autores observaram ainda que a alimentação foi o item de produção mais representativo no custo total com 59,7\% de participação, estando diretamente relacionado à densidade de estocagem.

Com base nos resultados apresentados por Souza et al. (2014), a viabilidade econômica e financeira, com produtividade média de 131,5 quilos de tambaqui por metro cúbico, com retorno do capital investido em 7,5 anos, taxa interna de retorno de $7,12 \%$ e relação benefício/custo maior que 1 . Tornando o investimento economicamente viável, uma vez que $\mathrm{RB} / \mathrm{C}$ é sempre maior que 1 e o valor presente líquido, maior que zero, sendo uma atividade de baixo risco. 
Segundo Costa et al. (2017), a produção de tambaqui curumim na região metropolitana de Manaus mostrou ser uma atividade de alto risco, pois apenas uma empresa de médio porte do ramo de beneficiamento obteve lucro (3,65\%), e outras duas médias empresas, vende um produto de $700 \mathrm{~g}$ pelo preço de $500 \mathrm{~g}$ de peixe, o que gerou prejuízo financeiro. Apesar de este produto ser altamente demandado no Amazonas, a perenidade de seu fornecimento está comprometida em função do insucesso na produção.

A falta de rentabilidade está associada com elevadas médias de conversão alimentar pela falta de manejo alimentar adequado e baixo preço pago ao produtor (Costa et al., 2017). Os preços pagos ao tambaqui curumim próximo a Manaus foram 4,00 $\mathrm{R} \$ / \mathrm{kg}$ na própria comunidade, 3,50 R $\$ / \mathrm{kg}$ aos barraqueiros da praia e 2,50 $\mathrm{R} \$ / \mathrm{kg}$ a frigoríficos no ano 2001 (Oliveira et al., 2011). No mercado em Manaus, é vendido a 5,39 R \$/kg (Gomes et al., 2006) e em média 4,25 R $\$ / \mathrm{kg}$ (Costa et al., 2017). Contudo, só foi verificado êxito em peixes criados com $1 \%$ de alimentação em relação à biomassa, apresentando custo de total de produção 3,08 R \$/kg, sendo inferior ao preço de venda, sendo inviável economicamente a criação de tambaqui nas taxas de alimentação de 3 e $5 \%$ do peso vivo/dia (Gomes et al., 2006).

Comparando com outras espécies, Campos et al. (2007) encontraram resultados econômicos favoráveis à atividade de tilapicultura com uma Taxa Interna de Retorno (TIR) de 57\%. Furlaneto et al. (2006) analisando os fatores econômicos do cultivo de tilápia em tanques-rede $\left(18 \mathrm{~m}^{3}\right.$ e $\left.6 \mathrm{~m}^{3}\right)$ no Médio Paranapanema, observaram que a ração apresentava 70 e $71 \%$ do Custo Operacional Total, respectivamente. Segundo Campos et al., (2007), dentre os benefícios da criação de peixes em tanques-rede estão: a redução do espaço físico necessário à criação, maior controle e aproveitamento eficiente de ração, redução dos custos de produção, maior produtividade sem necessidade de aumento da área, menor investimento inicial (70\% menor que viveiros convencionais) e maior facilidade na despesca (Conte et al., 2008), tornando a atividade mais competitiva e sustentável.

A receita bruta (RB) e o lucro operacional mensal (LOM) dos empreendimentos com 8 e 16 tanques-rede não possibilitaram um salário-mínimo mensal de pró-labore ao usuário (Brabo et al., 2013). Da mesma forma, os índices de lucratividade (IL) obtidos em sua pesquisa demonstraram ser mais vantajoso o investimento em empreendimentos maiores. Furlaneto et al., (2006) encontraram uma lucratividade de 10\% para um projeto de criação de tilápias em 250 tanques-rede de 6 $\mathrm{m}^{3}$ no Estado de São Paulo.

Segundo Scorvo Filho et al., (1998) a piscicultura apresenta bons índices de lucratividade e de retorno de investimento, cultivo de diferentes espécies em diversos sistemas de produção, sendo que quanto mais intensivo for o sistema de produção e mais maior número de unidades de cultivo, mais rentável e com as melhores taxas de retorno será o empreendimento.

\section{Conclusão}

A criação de tambaqui em tanques-rede é um sistema de criação intensiva relativamente mais barata, fácil de manejar e com investimentos iniciais vantajosos quando comparada à piscicultura tradicional em viveiros escavados.

O manejo adequado desde seleção do local, aquisição de alevinos de qualidade, realização de repicagem, qualidade da água, alimentação adequada e manejo preventivo sanitário proporciona ótimo desempenho zootécnico com padronização em lotes, diminuição do tempo de criação e o sucesso produtivo.

Mas a criação intensiva em tanques-rede para espécie apresenta maior risco em relação à piscicultura tradicional, $\mathrm{e}$ para o sucesso da atividade ainda são necessários mão-de-obra capacitada, domínio tecnológico, assistência técnica especializada, bom planejamento e gestão da atividade, demonstrando a necessidade de mão de obra especializada, ou bom conhecimento técnico do produtor. 


\section{Agradecimentos}

A disciplina de Produção de Peixes em Tanques-rede e Gaiolas 2020/2 do Programa de Pós-graduação em Recursos Pesqueiros e Engenharia de Pesca da UNIOESTE/Campus de Toledo, que possibilitaram a realização deste trabalho.

\section{Referências}

Affonso, E. G., Barros, F. P., Brasil, E. M., Tavares-Dias, M. \& Ono, E. A. (2009). Indicadores fisiológicos de estresse em peixes expostos ao peróxido de hidrogênio $\left(\mathrm{H}_{2} \mathrm{O}_{2}\right)$. In: Tavares-Dias, M. (Org.). Manejo e sanidade de peixes em cultivo. Embrapa Amapá: Macapá. $346-360$

Aguilar-Manjarrez, J. \& Ross, L. G. (1995). Geographical information systems (GIS), environmental models para aquaculture development in Sinaloa State, Mexico. Aquaculture International. 3, 103-115.

Américo, J. H. P., Cicigliano, G. D. \& Carvalho, S. L. (2012). Avaliação de alguns parâmetros físico-químicos da água de uma piscicultura com sistema de cultivo em tanques-rede. Fórum Ambiental da Alta Paulista. 8(2), 60-71.

Ayrosa, L. M. S., Furlaneto, F. P. B., Ayrosa, D. M. R. \& Sussel, F. R. (2005). Piscicultura no médio Paranapanema: situação e perspectivas. Aquicultura e Pesca, São Paulo, 12, 27-32.

Ayroza, L. M. S. (2009). Criação de Tilápia-do-Nilo, Oreochromis niloticus, em tanques-rede, na Usina Hidrelétrica de Chavantes, Rio Paranapanema, SP/PR. (Tese de doutorado) - Universidade Estadual Paulista, Centro de Aquicultura. Jaboticabal, SP, Brasil.

Boyd, C. E. \& Tucker, C. S. (1998). Pond aquaculture water quality management. Kluwer Academic, Boston, USA. 700p.

Brabo, M. F, Flexa, C. E., Veras, G. C., Paiva, R. S. \& Fujimoto, R. Y. (2013). Viabilidade econômica da piscicultura em tanques-rede no reservatório da usina hidrelétrica de Tucuruí, estado do Pará. Informações Econômicas, 43(3), 56-64.

Brandão, F. R., Gomes, L. D. C., Chagas, E. C. \& Araújo, L. D. D. (2004). Densidade de estocagem de juvenis de tambaqui durante a recria em tanquesrede. Pesquisa agropecuária brasileira, 39(4), 357-362.

Campos, C. M. C., Ganeco, L. N., Castellani, D. \& Martins, M. I. E. G. (2007). Avaliação econômica da criação de tilápias em tanque-rede, município de Zacarias, SP. Boletim do Instituto de Pesca, v.33 (2), 225-261.

Carneiro F. C. P., Martins M. I. E. G. \& Cyrino J. E. P. (1999). Estudo de caso da criação comercial da tilápia vermelha em tanque-rede - Avaliação Econômica. Informações Econômicas. 29(8), 52-61.

Cartonilho, M. M. \& Jesus, R. S. (2011). Qualidade de cortes congelados de tambaqui cultivado. Pesquisa Agropecuária Brasileira, Brasília, 46(4), 344-350.

Chagas, E. C., Gomes, L. D. C., Martins Júnior, H., Roubach, R., \& Lourenço, J. N. D. P. (2005). Desempenho de tambaqui cultivado em tanques-rede, em lago de várzea, sob diferentes taxas de alimentação. Pesquisa agropecuária brasileira, 40(8), 833-835.

Chagas, E. C., Gomes, L. D. C., Martins Júnior, H. \& Roubach, R. (2007). Produtividade de tambaqui criado em tanque-rede com diferentes taxas de alimentação. Ciência Rural, Santa Maria-RS, 37(4), 1109-1115.

Chellapa, S., N.T. Chellappa, W.B., Barbosa, F.A., Huntingford \& Beveridge, M.C.M. (1995). Growth and production of the Amazonian tambaqui in fixed cages under different feeding regimes. Aquaculture International, 3, 11-21.

Companhia de Desenvolvimento dos Vales do São Francisco e do Parnaíba - CODEVASF. (2019). Brasília-DF. Manual de criação de peixes em tanquesrede. Sandoval Jr., P., Trombeta, T. D \& Mattos, B. O de. $3^{\text {a }}$ ed.

Coelho, S. R. C. \& Cyrino, J. E. O. (2006). Custos na produção intensiva de surubins em gaiolas. Informações Econômicas, São Paulo, 36 (4), 1-14.

Conte, L., Sonoda, D. Y., Shirota, R. \& Cyrino, J. E. P. (2008). Productivity and economics of Nile tilapia Oreochromis niloticus cage culture in south-east Brazil. Journal of Applied Aquaculture, 20, 18-37.

Costa, J. I., Gomes, A. L. S., Sabbag, O. J. \& Martins, M. I. E. G. (2017). Evaluation of tambaqui "curumim" production in earth ponds in the metropolitan region of Manaus-Brazil. Revista Científica Rural. 19(2), 174-183.

Dairiki, J. \& Silva, T. B. A. (2011). Revisão de literatura: exigências nutricionais do tambaqui - compilação de trabalhos, formulação de ração adequada e desafios futuros. EMBRAPA Amazônia Ocidental. Manaus-AM. 44 p.

Damasceno, A. K., Fogaça, F. H. S. \& Araujo, T. D. S. (2014). Otimização do processo de produção de surimi a partir de carne mecanicamente separada de tambaqui (Colossoma macropomum). In: VI Anais do Simpósio de Controle de Qualidade do Pescado. Santos-SP, Instituto de Pesca. 1, 67-69, 6.

Dantas Filho, J. V., Cavali, J., Nunes, C. T., Nóbrega, B. A., Gasparini, L. R. F., Souza, M. L. R., Porto, M. O., Rosa, B. L., Gasparotto, P. H. G., Pontuschka, R. B. (2021). Proximal composition, caloric value and price-nutrients correlation of comercial cuts of tambaqui (Colossoma macropomum) and pirarucu (Arapaima gigas) in diferente body weight classes (Amazon: Brazil). Research, Society and Development, $10(1)$, e23510111698.

Eroldogan, O. T., Kumlu, \& M. Aktaş, M. (2004). Optimum feeding rates for European sea bass Dicentrarchus labrax L. reared in seawater and freshwater. Aquaculture, 231, 501-515.

Eiras, J. C., Takemoto, R. M. \& Pavanelli, G. C. (2010). Diversidade dos parasitos de peixes de água doce do Brasil. Maringá-PR. Ed. Graf. Clichetec, 333 p. 
Feio, T. A. (2015). Diagnóstico da comercialização do pescado nas feiras de Manaus nos períodos de defeso e não defeso. (Dissertação Mestrado). Programa de Pós-graduação em Biologia de Água doce e pesca Interior. INPA Manaus, Amazonas, Brasil. 58 p.

Ferraz, A. F. (2004). Cultivo de Tambaqui e matrinxã em tanque-rede: relatório técnico dos experimentos realizados nas Unidades de Observação do lago do Calado, lago do Puraquequara e lago do Limão, no Estado do Amazonas. IDAM. Manaus-AM. 176p.

Filho, M. D. (2001). Criação de peixes em tanques-rede. SENAR- Sindicato Rural, São Paulo-SP.

Fogaca, F. H. S., Savay-Da-Silva, L. K., Prentice-Hernández, C., Teodoro, M. S., Carvalho, L. M., Araujo, T. D. S., Pereira, A. M. L., Pedroso, A. L., Cassol, G. Z., Ribeiro, J. S., Dias, J. N., Magalhaes, J. A., Castro, K. N. C., Perfeito, M. L. G., Mellado, M. S., Quadros, C. C., Reis, P. S., Oliveira, T. M., Bertolini, W. \& Silva, D.A. Tecnologias para o Processamento do Tambaqui (Colossoma macropomum). Embrapa Agroindústria de Alimentos. Rio de Janeiro, RJ. Comunicado técnico $131.51 \mathrm{p}$.

Fracalossi, D. M., Rodrigues, A. P. O., Silva, T. S. C. \& Cyrino, J. E. P. (2012). Técnicas experimentais em nutrição de peixes. In: Fracalossi, D.M. \& Cyrino, J.E.P. NUTRIAQUA: nutrição e alimentação de espécies de interesse para a aquicultura brasileira. $1^{\mathrm{a}}$ ed. Florianópolis: Sociedade Brasileira de Aquicultura e Biologia Aquática. 37-63.

Franco, M. L. R. S, Franco, N. P., Gasparino, E., Dorado, D. M., Prado, M. \& Vesco, A. P. D. (2013). Comparação das peles de tilápia do Nilo, pacu e tambaqui: histologia, composição e resistência. Archivos de Zootecnia, 622(37), 21-32.

Freitas, R. A. (2011). Desempenho produtivo e avaliação econômica do cultivo de tambaqui (Colossoma macropomum) em tanques-rede, sob diferentes densidades de estocagem no lago Tupé. (Dissertação de Mestrado) Programa de Pós-Graduação em Ciências Pesqueiras nos trópicos. Universidade Federal do Amazonas, Manaus, Amazonas, Brasil. 61p.

Furlaneto, F. P. B., Ayroza, D. M. M. R. \& Ayroza, L. M. S. (2006). Custo e rentabilidade da produção de tilápia (Oreochromis spp.) em tanque-rede no médio Paranapanema, estado de São Paulo, safra 2004/05. Informações econômicas, São Paulo, 36(3), 63-69.

Furlaneto, F. P. B., Ayroza, D. M. M. R. \& Ayroza, L. M. S. (2010). Análise econômica da produção de tilápia em tanques-rede, ciclo de verão, região do médio Paranapanema, estado de São Paulo, 2009. Informações Econômicas, São Paulo, 40(4), 5-11.

Gandra, A.L. (2010). O mercado de pescado da região metropolitana de Manaus. Série: O mercado do pescado nas grandes cidades latino-americanas. Infopesca, 1, 1-91.

Goddard, S. (1996). Feed management in intensive aquaculture. Chapman \& Hall, New York, USA, 194p.

Gomes, L. C., Chagas, E. C., Martins-Junior, H., Roubach, R., Ono, E. A. \& Lourenço, J. N. P. (2006). Cage culture of tambaqui (Colossoma macropomum) in a central Amazon floodplain lake. Aquaculture 253, 374-384.

Gomes, L.C., Simões, L.N. \& Araujo-Lima, C.A.R.M. (2010). Tambaqui (Colossoma macropomum). In: BALDISSEROTTO, B., GOMES, L.C. (Ed.). Espécies nativas para piscicultura no Brasil. Ed. UFSM, Santa Maria, Rio Grande do Sul, 175-204.

Goulding, M. \& Carvalho, M. L. (1982). Life history and management of the tambaqui (Colossoma macropomum, Characidae): an important Amazonian food fish. Revista Brasileira de Zoologia. 1(2), 107-133.

Guidelli, G, Tavechio, W. L. G., Takemoto, R. M \& Pavanelli, G. C. Relative condition factor and parasitism in anostomid fishes from the floodplain of the Upper Paraná River, Brazil. Veterinary Parasitology. 177, 145-151.

Halide, H., Stigebrand, A, Rehbein, M. \& Mckkinnon, A. D. (2009). Developing a decision support system for sustainable cage aquaculture. Environmental Modelling \& Software. 24, 649-702.

Hayashi, C., Boscolo, W. R., Soares, C. M. \& Meurer, F. (2002) Exigência de proteína digestível para larvas de tilápia do Nilo (Oreochromis niloticus) no período de reversão sexual. Revista Brasileira de Zootecnia, 31(2), 823-828.

Honda, E. M. S. (1974). Contribuição ao conhecimento da biologia de peixes do Amazonas. II-Alimentação de tambaqui, Colossoma bidens (Spix). Acta Amazonica, 4(2), 47-53.

Institute of Food Science \& Technology - IFST. (1993). Shelf life of foods: guidelines for its determination and prediction. London, UK: Institute of Food Science \& Technology. 78 p.

Instituto Brasileiro de Geografia e Estatística - IBGE. (2020). Produção da aquicultura. Pesquisa da Pecuária Municipal. 2020. ttps://sidra.ibge.gov.br/tabela/3940. Acesso em 20/11/20.

Jobling, M. (1994). Fish bioenergetics. Chapman \& Hall. London, England. 294p.

Karakassis, I., Tsapakis, M., Hatziyanni, E., Papadopoulou, K.N. \& Plaiti, W. (2000). Impact of cage farming of fish on the seabed in three Mediterranean coastal areas. ICES Journal of Marine Science. 57, 1462-1471.

Kubitza, F. (1998). Qualidade da água na produção de peixes. Panorama da Aquicultura. 8(46), 35-41.

La Rosa, T., Mirto, S., Mazzola, A.\& Maugeri, T.L. (2004). Benthic microbial indicators of fish farm impact in a coastal area of the Thyrrenian Sea. Aquaculture. 230, 153-167.

Lemos, J. G, Tavares-Dias, M., Sales, R. S. A., Nobre-Filho, G. R. \& Fim, J. D. I. (2007). Parasitos nas brânquias de Brycon amazonicus (Characidae, Bryconinae) cultivados em canais de igarapé do Turumã-Mirim, estado do Amazonas, Brasil. Acta Scientiarum Biological Sciences. 29, 217-222.

Leonardo, A. F. G., Baccarin, A. E., Martins, M. I. E. G. \& Correia, C. F. (2012). Avaliação zootécnica e econômica da produção em tanques-rede em represa rural no vale do Ribeira. Pesquisa \& Tecnologia. 9(1), 1-9. 
Lima, C. S., Bonfim, M. A. D., Siqueira, J. C., Ribeiro, F. B. \& Lanna, E. A. T. (2016). Crude Protein Levels in the Diets of Tambaqui, Colossoma macropomum (CUVIER, 1818), Fingerlings. Revista Caatinga, Mossoró, 29(1), 183-190.

Liranço, A. D. D. S., Romagosa, E., \& Scorvo-Filho, J. D. (2011). Desempenho produtivo de Pseudoplatystoma corruscans estocados em sistemas de criação: semi-intensivo (viveiro escavado) e intensivo (tanque-rede). Ciência Rural. 41(3), 524-530.

Lobo, F. P., Cintra, L. C., Varela, E. S., Alves, A. L., Villela, L. C. V., Silva, N. M. A., Paiva, S. R. \& Caetano, A. R. (2015). Novo genome assembly of the South American freshwater fish Tambaqui (Colossoma macropomum). Plant \& Animal Genome Conference. 23.

Morais, I. S. de \& O’Sullivan, F. L. de A. (2017). Biologia, habitat e cultivo do tambaqui Colossoma macropomum (CUVIER, 1816). Scientia Amazonia. 6(1), 81-93.

Maeda, L. S. (1998). Diagnóstico da piscicultura na região de produção em torno de Manaus. (Monografia de graduação) Engenharia de Pesca, Universidade do Amazonas, Manaus, Brasil.

Mallasen, M., do Carmo, C. F., Tucci, A., de Barros, H. P., Rojas, N. E. T., da Fonseca, F. S., \& Yamashita, E. Y. (2018). Qualidade da água em sistema de piscicultura em tanques-rede no reservatório de Ilha Solteira, SP. Boletim do instituto de pesca. 38(1), 15-30.

Marcos, R., Povh, J. A., Fornari, D. C., Oliveira, C. A. L. de, Ribeiro, R. P., Lopera-Barrero, N. M., Corrêa Filho, R. A. C., Abreu, J. S. de \& Murari, P. J. F. (2016). Weight gain and morphometric growth of genetically improved tambaqui (Colossoma macropomum). Ciências agrárias. 37(4), 2521-2528.

Marengoni, N. G. (2006). Produção de tilápia do Nilo, Oreochromis niloticus (linhagem chitralada), cultivada em tanques-rede, sob diferentes densidades de estocagem. Archivos de Zootecnia, 55(210), 127- 138.

Meer, M. B., Herwaarden, H. Van \& Verdegem, M. C. J. (1997). Effect of number of meals and frequency of feeding on voluntary feed intake of Colossoma macropomum (Cuvier). Aquaculture Research, 28, 419-432.

Mendonça, P. P., Vidal-Junior, M. V., Polese, M. F., Santos, M. V. B., Rezende, F.P. \& Andrade, D. R. (2012). Morphometrical development of tambaqui (Colossoma macropomum, Cuvier, 1818) under different photoperiods. Revista Brasileira de Zootecnia, 41(6), 1337-1341.

Menezes, J. T. B., Queiroz, L. J., Doria, C. R. C. \& Menezes Jr, J. B. (2008). Avaliação espermática pós descongelamento em tambaqui, Colossoma macropomum (Cuvier, 1818). Acta Amazônica. 38(2), 365-368.

Moccia, R.D. \& Reid, G.K. (2007). Aquaculture Sustainability: Developing Concepts of a Decision Support Toll for Licencing Freshwater Cage Aquaculture in Ontario. Bulletin of Aquaculture Association of Canadá, Special Publication. 12, 106-114.

Moro, G. V., Torati, L. S., Luiz, D. de B. \& Matos, F. T. de. (2013). Monitoramento e manejo da qualidade da água em pisciculturas. In: Rodrigues, A. P. O., Lima, A. F., Alves, A. L., Rosa, D. K., Torati, L. S., Santos, V. R. V. dos (Ed.). Piscicultura de água doce: multiplicando conhecimentos. Brasília, DF: Embrapa. 141-169.

Nascimento, S. C. O. (2007). Avaliação da sustentabilidade do projeto de piscicultura Curupati-peixe no açude Castanhão, Jaguaribara-CE. (Dissertação mestrado) - Universidade Federal do Ceará. Fortaleza, Ceará, Brasil.

Neto, E. B. B., Prado, G. F., Prado, G. A. F. \& Sousa, R. G. C. (2017). Engorda de tambaquis (1 a 3 kg) arraçoados com dietas contendo 22 e $28 \%$ de proteína bruta. Scientia Amazonia, 6(1), 1-8.

Oliveira, A. C. B., Pedroti, V., Costa, J. I., Yamamoto, K.C. \& Freitas, R. A. (2009). Cultivo de Tambaqui em Tanques-Rede com Repicagem na Unidade Familiar de Produção de São João do Tupé. In: Anais XVI Congresso Brasileiro de Engenharia de Pesca. Manaus, Amazonas. 1, 192-197.

Oliveira, A. C. B., Yamamoto, K. C., Takahashi, M. S. de Q. \& Freitas, R. A. (2011). Unidade familiar de produção de peixes em tanques-rede no lago Tupé. In BioTupé: Meio Físico, Diversidade Biológica e Sociocultural do Baixo Rio Negro, Amazônia Central - 3, 477-494.

Oliveira, E. G., Pinheiro, A. B., de Oliveira, V. Q., da Silva Júnior, A. R. M., de Moraes, M. G., Rocha, Í. R. C. B. \& Costa, F. H. F. (2012). Effects of stocking density on the performance of juvenile pirarucu (Arapaima gigas) in cages. Aquaculture, 370, 96-101, 2012.

Oliveira, M. D. S., Luiz, D. D. B., Martins, G. D. S. \& Dos Santos, V. R. V. (2020). Net cage tambaqui farming: microbiological quality, nutritional value and yield. Embrapa Pesca e Aquicultura. Brasil. Archivos Zootecnia. 69(265), 66-71.

Oliveira, M. O. dos S., Luiz, D. de B., Santos, V. R. V. dos, Oliveira, E. H.S. de \& Martins, G. A. de S. (2019). Quality and safety aspects of the tambaqui (Colossoma macropomum) and painted from amazon (Pseudoplatystoma reticulatum x Leiarius marmoratus). Revista Desafios. 6, 10-16.

Ono, E.A. \& Kubitza. (1999). Cultivo de peixes em tanques-rede. 2 ed.rev. E ampl. Jundiaí: F. Kubitza. 68 p.

Pavanelli, G. C., Eiras, J. C. \& Takemoto, R. M. (2008). Doença de peixes, profilaxia, diagnóstico e tratamento. Ed.UEM, Maringá-PR. 311 p.

Pedrazzani, A. S., Molento, C. F. M., Carneiro, P. C. F. \& Castilho, M. F. (2007). Ciência e bem-estar de peixes: uma visão de futuro do mercado consumidor Panorama da Aquicultura. Rio de Janeiro - RJ. Disponível em: http://www.prp.ufla.br/wp-content/uploads/2011/08/bem-estar-em-peixes.pdf $>$ Acesso em: 20 nov. 2020.

Pedroza Filho, M. X., Rodrigues, A. P. O. \& Rezende, F. P. (2016). Dinâmica da produção de tambaqui e demais peixes redondos no Brasil. Boletim Ativos da Aquicultura. CNA BRASIL. 7, 1-7.

Peixe BR. (2020). Anuário 2019. Peixe BR da piscicultura. 136p.

Perazza, C. A., Menezes, J. T. B., Ferraz, J. B. S., Pinaffi, F. L. V., Silva, L. A., Hilsdorf, A. \& W. Silva. (2016). Lack of intermuscular bones in specimens of Colossoma macropomum: Na unusual phenotype to be incorporated into genetic improvement programs. Aquaculture. 472(1), 57-60. 
Pereira, A. S., Shitsuka, D. M., Parreira, F. J. \& Shitsuka, R. (2018). Metodologia da pesquisa científica. [e-book]. Santa Maria. Ed. UAB/NTE/UFSM. Disponível em: https://repositorio.ufsm.br/bitstream/handle/1/15824/Lic_Computacao_MetodologiaPesquisa-Cientifica.pdf?sequence=1.

Prochmann, A. M. \& Tredezini C. A. O. (2002). A piscicultura em Mato Grosso do Sul como instrumento de geração e renda na pequena propriedade. Fundação Cândido Rondon - UFMS. Campo Grande, MS, Brasil.

Ramos, F. C. P., Lourenço, L. F. H., Joele, M. R. S. P., Lima, C. L. \& Ribeiro, S. C. A. (2016). Tambaqui (Colossoma macropomum) sous vide: characterization and quality parameters Sous vide de tambaqui (Colossoma macropomum): caracterização e parâmetros de qualidade. Semina: Ciências Agrárias, Londrina, 37(1), 117-130.

Resende, E. K. (2009). Pesquisa em rede em aquicultura: bases tecnológicas para o desenvolvimento sustentável da aquicultura no Brasil. Revista Brasileira de Zootecnia. (38), 52-57.

Rodrigues, A. P. O. (2014). Nutrição e alimentação do tambaqui (Colossoma macropomum). Boletim do Instituto de Pesca, 40(1), 135-145.

Rowland, S. J., Mifsuda, C., Nixon, M. \& Boyd, P. (2006). Effects of stocking density on the performance of the Australian freshwater silver perch (Bidyanus bidyanus) in cages. Aquaculture, 253, 301-308.

Rolim, P. R. (1995) A infraestrutura básica para a criação de peixes no Amazonas. In: Val, A. L. \& Honczaryk, A. (Ed.). Criando peixes na Amazônia. Manaus: Instituto Nacional de Pesquisas da Amazônia. 7-16.

Rotta, M. A. \& Queiroz, J. F. (2003). Boas práticas de manejo (BPMs) para produção de peixes em tanques-redes. Corumbá-MS: Embrapa Pantanal. 47, 27p.

Sabaini, D. S., Casagrande, L. P. \& Barros, A. F. de. Viabilidade econômica da criação do pintado da Amazônia (Pseudoplatystoma spp.) em tanques-rede no estado de Rondônia, Brasil. Boletim do Instituto de Pesca, 41(4), 825-835.

Salaro, A. L. \& Lambertucci, D. M. (2011). Criação de peixes em tanques-rede. $3^{\text {a }}$. Ed. Senar: Brasília, DF, Brasil. 104 p.

Santos, E. F., Tavares-Dias, M., Pinheiro, D. A., Neves, L. R., Marinho, R. D. G. B., \& Dias, M. K. R. (2013). Fauna parasitária de tambaqui Colossoma macropomum (Characidae) cultivado em tanque-rede no estado do Amapá, Amazônia oriental. Acta Amazonica, 43(1), 105-111.

Santos, S. D. O. \& Da Silva, C. A. (2017). Qualidade de água na engorda de tambaquis criados em tanque-rede. In: Anais do Seminário de Iniciação Científica e Pós-Graduação da Embrapa Tabuleiros Costeiros. Embrapa Tabuleiros Costeiros, Aracaju, SE, Brasil. 7.

Santos, E. L., Soares, A. C. L., Tenório, O. L. D., Soares, E. C., Silva, T. J. \& Gusmão Júnior, L. F. (2018). Desempenho de tambaquis (Colossoma macropomum) submetidos a restrição alimentar e a realimentação em tanques-rede. Arquivo Brasileiro de Medicina Veterinária e Zootecnia, 70(3), 931-938.

Scorvo Filho, J.D., Martin, N. B. \& Ayroza, L. M.S.C. (1998). Piscicultura em São Paulo: custos e retornos de diferentes sistemas de produção na safra 1996/97. Informações Econômicas, 28(3), 41-60.

Scorvo Filho, J.D., Pinto, C.S.R.M., Verani, J.R. \& Silva, A.L. (2006). Custo operacional de produção da criação de tilápias vermelha da Flórida e Tailandesa em tanque-rede de pequeno volume. Informações Econômicas, São Paulo, 36(10), 71-79.

Sidonio, L., Cavalcabti, I., Capanema, L., Morch, R., Magalhães, G., Lima, J., Burns, V., Alves Sr. A. \& Mungioli, R. (2012). Panorama da aquicultura no Brasil: desafios e oportunidades. BNDES setorial. 35, 421-463.

Signor, A. A., Reidel, A., Coldebella, A., Ferreira, H. K. A., Signor, F. R. P., Buglione Neto, C. C. \& Watanabe, A. L. (2020). Densidade de estocagem de jundiá (Rhamdia quelen) em tanques-rede na fase inicial. Brazilian Journal of Development. v.6 (7).

Silva, C. A. D. \& Fujimoto, R. Y. (2015). Crescimento de tambaqui em resposta a densidade de estocagem em tanques-rede. Acta Amazonica, 45(3), 323-332.

Silva, C.A. (2015). Boas Práticas de Manejo na Criação de Tambaquis em Tanques-Rede, Circular Técnica Embrapa, Aracajú, SE, Brasil.11p.

Silva, J. R., Rabenschlag, D. R., Feiden, A. A, Boscolo, W. R. B, Signor, A. A. \& Bueno, G. W. (2012). Produção de pacu em tanques-rede no reservatório de Itaipu, Brasil: retorno econômico. Archivos de Zootecnia, 61(234), 245-254.

Souza, R. A., Padua, D. M. C., Oliveira, R. P. de C. \& Maia, T. C. B. (2014). Análise econômica da criação de tambaqui em tanques-rede: estudo de caso em assentamento da reforma agrária. Custos e @ gronegócio on line. 10(1), 253-268.

Taniguchi, F., Kato, H. D. A. \& Tardivo, T. (2014). Definições e estrutura: tanque-rede. Embrapa Pesca e Aquicultura-Fôlder/Folheto/Cartilha (INFOTECAE). Palmas, TO, Brasil. 8p.

Tavares-Dias, M., Martins, M. L. \& Moraes, F. R. (2001). Fauna parasitária de peixes oriundos de pesque-pague do município de Franca, São Paulo, Brasil. I. Protozoários. Revista Brasileira de Zoologia. 18, 67-79.

Tavares-Dias, M., Araújo, C. S. O., Porto, S. M. A., Viana, G. M. \& Monteiro, P. C. (2013). Sanidade do Tambaqui Colossoma macropomum nas fases de larvicultura e alevinagem. Macapá: Embrapa Amapá, Manaus: Universidade Nilton Lins, Instituto de Pesquisas da Amazônia.

Tavares-Dias, M., Silva, C., Correa, R. D. O., Martins Junior, H., Yoshioka, E., Araujo, J. D. C. \& Fogaca, F. D. S. (2018). Boas práticas para a produção de tambaqui em tanques-rede: da implantação à despesca. Embrapa Amapá-Comunicado Técnico (INFOTECA-E).

Val, A. L., Rolim, P. R. \& Rabelo, H. (2000). Situação atual da aqüicultura na Região Norte. In: Valente, W.C., Poli, C.R., Pereira, J.A., Borghetti, J.R. (Ed.). Aquicultura no Brasil: bases para um desenvolvimento sustentável. Brasília: CNPq, MCT, 247-266.

Young, W.F., Horth, H., Crane, R., Ogden, T. \& Arnott, M. (1996). Taste and odour threshold concentrations of potential potable water contaminants. Water Research. 30(2), 331-340.

Zat, M., \& Benetti, A. D. (2011). Remoção dos compostos odoríferos geosmina e 2-metilisoborneol de águas de abastecimento através de processos de aeração em cascata, dessorção por ar e nanofiltração. Engenharia Sanitaria e Ambiental. 16(4), 353-360. 